\title{
Situación actual sobre la violencia política de género en México: Estereotipos que dificultan el derecho político de la mujer de acceder a cargos públicos
}

\author{
Current Situation on Gender-based Political Violence in Mexico: \\ Stereotypes That Hinder Women's Political Right to Access Public Office
}

Rogelio López Sánchez ${ }^{1}$

Recibido: 25/08/2020 Aceptado: 10/11/2020 Publicado: 30/11/2020

\section{Resumen}

El paradigma actual empleado por los órganos encargados de procurar y administrar justicia, además de carecer de una visión de intersección del género, reproducen estereotipos que perpetúan una cultura patriarcal, misógina y anquilosada de roles, disminuyendo y afectando de manera grave la participación política de la mujer así como su acceso efectivo a los cargos de representación política. Por ello, el impacto y trascendencia en la línea de investigación será a través del aporte original forense que brindará herramientas epistemológicas para la solución de casos, combinado con el riguroso estudio de las principales teorías que auxilian en la adopción del enfoque de género transversal y de derechos humanos de las mujeres. de la violencia política de género contra la mujer basada en la interseccionalidad de género.

El aporte principal del mismo radica en el estudio crítico del modelo que actualmente emplea el Tribunal Electoral del Poder Judicial de la Federación así como los Tribunales locales cuando sancionan conductas relativas a la violencia política de género. En principio, por la ausencia de tipos penales e infracciones administrativas en la legislación, pero sobre todo, por la carencia de un enfoque interseccional de género que evalúe las pruebas bajo un modelo diverso al actual, más flexible y acorde a los estándares del Derecho Internacional

Palabras clave: Interseccionalidad de género, políticas públicas, derechos humanos de la mujer, derecho internacional.

\footnotetext{
${ }^{1}$ Doctor en Derecho Constitucional por la Universidad de Jaén, España. Abogado Postulante en materia de Amparo y Derechos Humanos por la Firma Legal: OGAIUS México. Director de la Academia Libre de Derechos Humanos (México). Contacto: academia@aldh.mx
} 


\begin{abstract}
The current paradigm used by the bodies in charge of procuring and administering justice, in addition to lacking a vision of intersection of gender, reproduce stereotypes that perpetuate a patriarchal, misogynistic and role stagnant culture, diminishing and seriously affecting the political participation of the women as well as their effective access to positions of political representation. Therefore, the impact and transcendence in the line of investigation will be through the original forensic contribution that will provide epistemological tools for the solution of cases, combined with the rigorous study of the main theories that aid in the adoption of the transversal gender approach and human rights of women. of political gender violence against women based on gender intersectionality.

Its main contribution lies in the critical study of the model currently used by the Electoral Tribunal of the Federal Judicial Branch as well as the local Courts when they sanction conduct related to political gender violence. In principle, due to the absence of criminal offenses and administrative offenses in the legislation, but above all, due to the lack of an intersectional gender approach that evaluates evidence under a different model than the current one, more flexible and in accordance with the standards of International Law.
\end{abstract}

Keywords: Gender intersectionality, public policies, women's human rights, international law, international right.

\title{
1. Introducción: el enfoque interseccional de género
}

Actualmente, el Estado mexicano sufre una crisis institucional por niveles alarmantes de violencia contra la mujer. Según datos estadísticos de la ONU (2019), entre diez y nueve mujeres son asesinadas cada día en México. Este hecho significa la cifra más alta en toda la historia contemporánea del país. Desde el año 2015 a la fecha, se tiene registro de 3,578 feminicidios a nivel nacional y se han declarado en el país alertas de género en 13 Estados y casi 90 municipios por causas graves, es decir, donde está en peligro la vida e integridad de las mujeres. Conforme a cifras del Secretariado Ejecutivo tan sólo en 2019, se cometieron 1006 feminicidios.

De acuerdo con la Encuesta Nacional de Victimización y Percepción de la Seguridad Pública (ENVIPE) realizada por el INEGI (2019), se tuvo como resultado que en ese mismo año, el $90 \%$ de los delitos sexuales fueron cometidos en contra de mujeres mostrando un alarmante panorama en el cual el lugar más inseguro son las áreas públicas a diferencia de los hombres, mostrando incluso un $26 \%$ a la alza en relación con su propio hogar. La propia Encuesta Nacional sobre la Dinámica de las Relaciones en los Hogares (2016) indica también niveles muy altos de violencia de algún tipo ejercida por las parejas en contra de las mujeres (64\%).

Lo anterior implica que el incumplimiento de las obligaciones contraídas por el Estado mexicano al suscribir la Convención Americana de Derechos Humanos (1981) ha quedado 
al descubierto en el plano interamericano, a través de las distintas sentencias proferidas por la Corte Interamericana de Derechos Humanos desde hace casi una década (Caso González y otras, 2009; Caso Rosendo Cantú y otra, 2010; Fernández Ortega y otros, 2010), ya que en las mismas se condenó al Estado mexicano por violencia de género institucionalizada, en virtud de los hechos probados que atentaban contra la integridad y la vida de las demandantes.

La violencia política de género constituye uno de los ataques frontales a la dignidad humana de las mujeres al disminuir sus oportunidades de participación y denigrar su papel en la conformación de Estado, en cualquiera de sus modalidades: física, psicológica, económica, sexual, simbólica, entre otras; con la particularidad que se desarrollan específicamente en la persecución (periodos electorales) o ejercicio de representación política, con una carga particular por ser mujer. Sin embargo, es posible argumentar que la violencia política de género es de rango estructural (Otálora, 2017), al existir y afectar en la persecución de representación política aun cuando es fuera de los periodos asignados.

A pesar de este panorama desolador, existen algunos avances alcanzados en materia de integración paritaria de algunos órganos de representación política. Al día de hoy, el Congreso federal está compuesto por el $48 \%$ y $49 \%$ de espacios (Cámara de Diputados y Senadores respectivamente) para legisladoras. Las legislaturas de las Entidades Federativas en su mayoría con integración paritaria (23 de 27 Congresos que tuvieron elecciones en 2018), en tanto que un porcentaje de apenas el 23 \% de los Municipios tienen Presidentas Municipales (INEGI, 2019). Es decir, en la mayoría de los municipios de las Entidades Federativas no se alcanza la paridad transversal, por lo que a partir de junio de 2019 entró en vigor la reforma que obliga a integrar los órganos del poder público.

Este orden evolutivo de las medidas para integrar de manera paritaria los órganos públicos, debería ser paralela al nivel de cultura cívica y política, lo cual no es así, ya que durante 2018 se han registrado el nivel más alto de denuncias por violencia política de género en el país. Tan sólo durante el pasado proceso electoral 2017-2018 se presentaron un total de 107 quejas ante el INE y Poder Judicial Federal, mientras que en las Entidades de la República se registraron un total de 19. Por su parte, las denuncias ante la FEPADE por violencia política de género constituyeron un total de 47 carpetas, judicializándose sólo el 3\% de aquéllas.

Las Entidades Federativas con más denuncias son Chiapas, Chihuahua, Ciudad de México, Campeche y Baja California, aunado a que el pasado proceso electoral ha sido el más violento de toda la historia política moderna, registrándose un nivel alarmante de violencia en contra de mujeres, lo cual ha derivado en la muerte de 17 candidatas. Ahora bien, es necesario resaltar que las formas de socialización política no han sido ajenas a las transformaciones de la era moderna, lo cual ha promovido su mutación hacia el ámbito digital. Particularmente durante el proceso electoral 2017-2018, el medio empleado con más frecuencia para comunicarse fue internet (94\%), claramente decantado en las diferentes Redes Sociales, siendo los más activos políticamente las personas de 18 a 29 años (27\%). En el Informe de violencia política a través de las tecnologías 
contra las mujeres en México, se destaca de manera importante como ha migrado la violencia de género hacia este ámbito, constituyendo así una de las nuevas formas directas e indirectas de discriminación y violencia en contra de la participación política de la mujer, siendo los motivos más frecuentes: el juicio de carácter sexual, la objetualización sexual, agresiones contra la familia, roles de género y la apariencia.

En el mismo sentido, escasean criterios jurisdiccionales y orientadores para sensibilizar sobre el fenómeno de la violencia política de género en contra de mujeres indígenas. Tal es el caso de las mujeres de la comunidad de Guevea de Humboldt, Tehuantepec, quienes vieron violados sus derechos políticos electorales hasta que en 2016 , cuando se les reconoció tal prerrogativa y efectivamente ejercieron su voto. Este escenario violento ha propiciado la creación del Protocolo para Atender la Violencia Política Contra las Mujeres, el cual surge como resultado del esfuerzo conjunto interdisciplinar llevado a cabo entre distintas dependencias públicas, convirtiéndose en una de las herramientas más valiosas para atender de manera integral la violencia política por razón de género. Sin embargo, además de los elementos de discriminación y violencia directa antes descritos, existen en el plano discursivo y en la construcción social otros tipos de violencia indirecta que afectan de manera grave los esfuerzos de la mujer en su camino para alcanzar la igualdad real y efectiva.

La violencia política de género en medios digitales debe ser prevenida y castigada a través de la aplicación de estándares hermenéuticos y racionales más flexibles (de los tradicionales) a fin de que se ajusten a la realidad digital permitiendo la construcción de criterios jurisprudenciales género-sensitivos y legislación reglamentaria que prevenga y castigue dichas conductas, ya que en los medios digitales se suele invisibilizar la violencia producida como consecuencia de la propia dinámica etérea y la vertiginosa forma de comunicación política digital, pero sobre todo, que los órganos encargados de procurar y administrar justicia minimizan la naturaleza de las infracciones, obstaculizando así el derecho de las mujeres a que se les administre justicia.

Es importante considerar el género más como una categoría de análisis que de personas, haciendo énfasis en innovadoras formas de ver la articulación del poder en una cultura dada. De este modo, Butler (2007), sugiere hacer más bien una coalición abierta para la creación de identidades más atemporales y abiertas que en función de objetivos concretos, en el entendido de encontrar las múltiples similitudes y divergencias que existen en el género. Por lo que la mujer nunca será exhaustivo ni inclusivo, en palabras de (Butler, 2007, p.137),: porque el género no siempre se constituye de forma coherente o consistente en contextos históricos distintos, y porque se entrecruza con modalidades raciales, de clase, étnicas, sexuales y regionales de identidades discursivamente constituidas. Así, es imposible separar el «género» de las intersecciones políticas y culturales en las que constantemente se produce y mantiene.)

Por ende, es necesario abogar por la participación de las mujeres, en plural y pluralizado. Es decir, que existan mujeres heterosexuales, bisexuales, lesbianas, transexuales, blancas, mestizas, afrodescendientes, indígenas de todas las comunidades, con y sin discapacidades de todos los tipos. No es sólo una mujer, sino que todas las mujeres 
deben sentir, por lo menos, que están siendo representadas ellas y sus intereses. Es decir, debe evitarse la discriminación interseccionada o transversal.

\section{Derechos humanos de la mujer}

La legislación más avanzada en materia de igualdad real y efectiva entre hombres y mujeres es la europea. España y Alemania se encuentran entre los primeros lugares en ofrecer oportunidades laborales y sociales para las mujeres. Los criterios de ambos países, así como del Tribunal de Justicia de las Comunidades Europeas, servirán para comprender los modernos criterios que han servido para solucionar casos difíciles en aquellas latitudes.

Existe una marcada diferencia entre el sistema europeo y el sistema americano de protección y defensa de los derechos de las mujeres. Mientras que el primer modelo cuenta con normas y directrices específicas para la defensa de estos derechos, en América Latina aún nos encontramos en una fase prematura de desarrollo de instrumentos para lograr la efectividad de los derechos. En nuestro continente, contamos con la Convención Americana sobre Derechos Humanos (1969), el Pacto Internacional de Derechos Civiles y Políticos (1966), la Declaración Americana de los Derechos y Deberes del Hombre (1948), el Protocolo Adicional a la Convención Americana en Materia de Derechos Económicos, Sociales y Culturales (Protocolo de San Salvador) (1998), y de manera específica, tenemos la Convención Interamericana sobre Nacionalidad de la Mujer (Montevideo, 1933), la Convención Interamericana sobre la Concesión de los Derechos Civiles a la Mujer (Bogotá, 1948), la Convención Interamericana sobre Concesión de los Derechos Políticos a la Mujer (Bogotá, 1948) y la Convención Interamericana para Prevenir, Sancionar y Erradicar la Violencia Contra la Mujer (Convención de Belém Do Pará, 1994).

En el sistema europeo se cuenta con el Tratado Constitutivo de la Comunidad Económica Europea (CEE) (2017), especialmente el artículo 13; la Carta de los Derechos Fundamentales de la Unión Europea (UE) (2000), particularmente los artículos 21, 23, 24, 25, 26 y 33; la Carta Social Europea (2000). A lo anterior se suman las distintas Directivas de la Comunidad Europea, entre las que destacan:

- La Directiva 2000/43/CE, relativa a la aplicación del principio de igualdad de trato de las personas independientemente de su origen racial o étnico (DO L 180 de 19 de julio de 2000);

- La Directiva 2000/78/CE del Consejo, relativa al establecimiento de un marco general para la igualdad de trato en el empleo y la ocupación (DO L 303 de 2 de diciembre de 2000);

- La Directiva 2004/113/CE de 13 de diciembre de 2004, por la que se aplica el principio de igualdad de trato entre hombres y mujeres al acceso a bienes y servicios y su suministro; $y$ 
- La directiva 2006/54/CE del Parlamento y del Consejo relativa a la aplicación de igualdad de trato e igualdad de oportunidades entre hombres y mujeres en asuntos de empleo y ocupación.

Por otra parte, en el sistema universal de defensa y protección para los derechos de la mujer contamos con:

- $\quad$ La Convención sobre los Derechos Políticos de la Mujer (1952);

- La Declaración sobre la Eliminación de la Discriminación contra la Mujer (1967);

- La Declaración sobre la Protección de la Mujer y el Niño en Estados de Emergencia o de Conflicto Armado (1974);

- La Convención sobre la Eliminación de todas las Formas de Discriminación contra la Mujer (1979) (conocida como CEDAW por sus siglas en inglés), así como su Protocolo Facultativo y su recomendación sobre la protección de la maternidad; y

- El Convenio 182 de la Organización Internacional del Trabajo (OIT) Relativo a la Revisión del Convenio sobre la protección de la Maternidad.

Asimismo, otro de los instrumentos internacionales, fue la IV Conferencia Mundial sobre las Mujeres, celebrada en Pekín en el año de 1995, en donde se reafirmó el compromiso celebrado con anterioridad en la Convención sobre la Eliminación de todas las Formas de Discriminación contra la Mujer de 1979. En dicha Conferencia se abordó el problema de la discriminación de facto hacia las mujeres, sustentando que.

"Para la eliminación de la discriminación contra la mujer no basta un cambio jurídico", sino que era necesario modificar los prejuicios y costumbres arraigados en una idea de inferioridad o superioridad basadas en el género" (Real, 1996, p.34)

Precisamente, esta última cuestión referente a la igualdad real y efectiva entre los hombres y mujeres ha sido redefinida por la doctrina constitucional contemporánea de los derechos fundamentales. En la actualidad, la fórmula del Estado Democrático y Social de Derecho (presente en gran parte de las constituciones europeas, pero ausente en el texto fundamental mexicano) ha permitido la reinterpretación del clásico modelo de igualdad formal o legal que predominó por largos años en los Estados de Derecho durante gran parte del siglo pasado, la cual reducía la igualdad a un mero asunto de legalidad, dejando de lado las nuevas necesidades y problemas sociales que exigían a la jurisdicción constitucional resoluciones ajustadas a un modelo de Estado más equitativo. Por ejemplo, el establecimiento de prestaciones sociales distintas a las mujeres trabajadoras no son las mismas que las otorgadas a los hombres, y sin embargo, esto no implica que se rompa la igualdad entre los sexos; incluso, algunas legislaciones como la alemana han ido más allá, (Ley Reguladora del Permiso de Paternidad y la Reducción de Jornada por Cuidado de Hijo) buscando fomentar la crianza de los hijos por parte de los padres, sin que esto perjudique los derechos sociales adquiridos por éstos. 
De tal forma, para algunos tratadistas la igualdad debiera ser entendida como:

"La concreción de criterios materiales para llevar a cabo el valor solidaridad, a través de la creación de las condiciones materiales para una libertad posible para todos, y en contribuir a la seguridad con la satisfacción de necesidades a quien no puede hacerlo por su propio esfuerzo" (Peces-Barbas, 199, p.283).

Así, los teóricos distinguen dos dimensiones en torno a la igualdad: la formal y la sustancial. La primera hace referencia al principio de la igualdad ante la ley. Ésta aparece como una exigencia de que todos los ciudadanos se hallen sometidos a las mismas normas y tribunales. Por otra parte, la igualdad material o sustancial, se encuentra íntimamente vinculada con el principio de Estado Democrático y Social de Derecho, conforme a dicha concepción material-formal de la igualdad, la dimensión jurídica no puede desconectarse de las condiciones políticas, económicas y sociales que gravitan sobre su realización, es decir, implica la integración de aquellas personas que han sido socialmente desfavorecidas por distintas circunstancias, como es el caso de las mujeres.

Sin duda alguna, la mayor parte de los criterios a nivel internacional y de legislación comparada en el ámbito europeo se inclinan hacia una concepción sustancial de la igualdad entre hombres y mujeres, procurando en mayor medida, la plena efectividad entre los derechos de ambos. En el sistema alemán por ejemplo, fue consagrado de manera expresa el principio de igualdad sustancial, a través de una reforma constitucional en el año de 1994, para quedar como sigue:

Artículo 3 [Igualdad ante la ley]

(1) Todas las personas son iguales ante la ley.

(2) El hombre y la mujer gozan de los mismos derechos. El Estado promoverá la realización efectiva de la igualdad de derechos de las mujeres y los hombres e impulsará la eliminación de las desventajas existentes2. (Artículo Constitucional 1994)

Sin duda alguna, esto se refiere a las medidas de acción positiva que debe realizar el Estado para mejorar la situación de los grupos vulnerables que históricamente se han encontrado en desventaja ante otros, como es el caso de las mujeres. Dichas medidas implementadas por el Estado nacieron en el derecho norteamericano y tuvieron como principal inspiración la cláusula de igualdad contenida en la decimocuarta enmienda de la declaración de derechos de esa nación. Desde aquella perspectiva, las acciones afirmativas constituyen:

"Cualquier medida, más allá de la simple terminación de una práctica discriminatoria, adoptada para corregir o compensar por una discriminación presente o pasada o para impedir que la discriminación se produzca en el futuro" (VIDA, 2003, p. 35)

${ }^{2}$ Señalamos con cursiva el texto añadido en la reforma. 
De esta forma, desde el punto de vista teórico, las medidas de acción positiva deben contar con tres características o elementos esenciales:

- Es indispensable que una persona se halle en una situación en desventaja por su pertenencia a determinado colectivo respecto del grupo dominante;

- La puesta en práctica de dicha medida deberá suponer un beneficio inmediato para esa persona o colectivo;

- Finalmente, la última característica está relacionada con la finalidad perseguida por la medida, es decir, debe tener como objeto poner fin a la situación de desventaja en la que se encuentra determinado colectivo, es decir, reducir los niveles de desigualdad. (VIDA, 2003, p. 35)

\section{Situación actual de la violencia política de género en México}

Desde la óptica forense, los órganos jurisdiccionales nacionales como los Tribunales Electorales locales y la Sala Superior también han sido reticentes en analizar desde otro enfoque la violencia política de género. Es decir, los órganos jurisdiccionales se han limitado a emplear los métodos probatorios tradicionales, a pesar de la existencia del Protocolo para Atender la Violencia Política Contra las Mujeres, antes referido, así como el elaborado año atrás por la Suprema Corte de Justicia de la Nación, denominado: Protocolo para juzgar con perspectiva de género. Por citar alguna evidencia, las infracciones más comunes son analizadas desde la óptica probatoria tradicional, sesgando los problemas hermenéuticos más complejos como la violencia simbólica que es ejercida continuamente en contra de la mujer. Como muestra y prueba de lo anterior, de un análisis de las resoluciones emitidas la Sala Superior del Tribunal Electoral del Poder Judicial de la Federación se obtuvieron los siguientes resultados.

Tabla 1

\begin{tabular}{|c|c|c|c|c|}
\hline \multicolumn{5}{|c|}{ SENTENCIAS EMITIDAS POR SALA } \\
\hline Sentencias & $\begin{array}{l}\text { Tipo de Violencia } \\
\text { ejercida }\end{array}$ & $\begin{array}{l}\text { ¿Emplea un } \\
\text { enfoque de } \\
\text { perspectiva } \\
\text { de género la } \\
\text { sentencia? }\end{array}$ & $\begin{array}{l}\text { ¿Obstaculiz a } \\
\text { el acceso a la } \\
\text { justicia de la } \\
\text { mujer? }\end{array}$ & $\begin{array}{c}\text { ¿Qué estereotipo } \\
\text { perpetúa la sentencia? }\end{array}$ \\
\hline SUP-JDC-156/2019 & Simbólica & Sí & Sí & $\begin{array}{l}\text { No explica qué tipo de } \\
\text { violencia es ejercida }\end{array}$ \\
\hline SUP-JDC-9/2019 & $\begin{array}{l}\text { Física, } \\
\text { psicológica, } \\
\text { económica }\end{array}$ & No & Sí & $\begin{array}{l}\text { Omite analizar el acoso } \\
\text { laboral como una forma } \\
\text { de violencia en contra } \\
\text { de la mujer }\end{array}$ \\
\hline
\end{tabular}




\begin{tabular}{|c|c|c|c|c|c|}
\hline \multicolumn{6}{|c|}{ SENTENCIAS EMITIDAS POR SALA } \\
\hline & Sentencias & $\begin{array}{l}\text { Tipo de Violencia } \\
\text { ejercida }\end{array}$ & $\begin{array}{c}\text { ¿Emplea un } \\
\text { enfoque de } \\
\text { perspectiva } \\
\text { de género la } \\
\text { sentencia? }\end{array}$ & $\begin{array}{c}\text { ¿Obstaculiz a } \\
\text { el acceso a la } \\
\text { justicia de la } \\
\text { mujer? }\end{array}$ & $\begin{array}{c}\text { ¿Qué estereotipo } \\
\text { perpetúa la sentencia? }\end{array}$ \\
\hline \multirow{2}{*}{\multicolumn{2}{|c|}{$\begin{array}{c}\text { SUP-JDC-1862/2019 } \\
\text { SUP-JDC-5/2017 }\end{array}$}} & \multirow[b]{2}{*}{ Violencia política } & \multirow[b]{2}{*}{ No } & \multirow[b]{2}{*}{ Sí } & $\begin{array}{l}\text { Omite analizar la } \\
\text { obstaculización del }\end{array}$ \\
\hline & & & & & $\begin{array}{l}\text { ejercicio a un cargo bajo } \\
\text { el enfoque de violencia } \\
\text { política de género }\end{array}$ \\
\hline \multicolumn{2}{|r|}{ SUP-REC-594/2019 } & $\begin{array}{l}\text { Violencia política } \\
\text { e institucionalizada }\end{array}$ & No & Sí & $\begin{array}{l}\text { Omite dar directrices } \\
\text { para encauzar la petición } \\
\text { de la mujer a la que se } \\
\text { le negó el acceso a la } \\
\text { justicia }\end{array}$ \\
\hline \multicolumn{2}{|r|}{ SUP-REP-116/2019 } & $\begin{array}{l}\text { Violencia } \\
\text { simbólica a través } \\
\text { del empleo de } \\
\text { lenguaje sexista }\end{array}$ & Sí & No & $\mathrm{N} / \mathrm{A}$ \\
\hline & \multirow[b]{2}{*}{ SUP-JE-115/2019 } & \multirow[b]{2}{*}{ Violencia política } & \multirow[b]{2}{*}{ No } & \multirow[b]{2}{*}{ Sí } & $\begin{array}{l}\text { Omite adoptar medidas } \\
\text { cautelares para la }\end{array}$ \\
\hline & & & & & $\begin{array}{l}\text { rapidez en la protección } \\
\text { de los derechos de la } \\
\text { afectada }\end{array}$ \\
\hline 8 & SUP-JE-43/2019 & \multirow{3}{*}{$\begin{array}{l}\text { Violencia política } \\
\text { por obstaculizar } \\
\text { el desempeño de } \\
\text { un cargo electoral } \\
\text { en condiciones de } \\
\text { igualdad }\end{array}$} & \multirow{3}{*}{ No } & \multirow{3}{*}{ Sí } & \multirow{3}{*}{$\begin{array}{l}\text { Falta de análisis } \\
\text { probatorio con enfoque } \\
\text { de género: prueba } \\
\text { dinámica }\end{array}$} \\
\hline 9 & SUP-JDC-158/2017 & & & & \\
\hline 10 & SUP-JE-107/2016 & & & & \\
\hline 11 & SUP-JE-102/2016 & $\begin{array}{l}\text { Violencia política } \\
\text { por obstaculizar } \\
\text { el desempeño de } \\
\text { un cargo electoral } \\
\text { en condiciones de } \\
\text { igualdad }\end{array}$ & Sí & Sí & $\mathrm{N} / \mathrm{A}$ \\
\hline \multirow{3}{*}{$\begin{array}{l}12 \\
13\end{array}$} & \multicolumn{2}{|l|}{ SUP-JDC-383/2018 } & \multirow{13}{*}{ Sí } & \multirow{13}{*}{ Sí } & \multirow{13}{*}{$\begin{array}{l}\text { Falta de análisis } \\
\text { probatorio con enfoque } \\
\text { de género: prueba } \\
\text { dinámica }\end{array}$} \\
\hline & \multicolumn{2}{|l|}{ SUP-JDC/357/2018 } & & & \\
\hline & \multicolumn{2}{|l|}{ SUP-REP-250/2018 } & & & \\
\hline 15 & SUP-REP-56/2018 & \multirow{10}{*}{$\begin{array}{l}\text { Violencia } \\
\text { simbólica a través } \\
\text { del empleo de } \\
\text { lenguaje con } \\
\text { estereotipos de } \\
\text { género durante una } \\
\text { campaña electoral } \\
\text { a través de radio o } \\
\text { televisión }\end{array}$} & & & \\
\hline 16 & SUP-REP-103/2017 & & & & \\
\hline 17 & SUP-REP-84/2017 & & & & \\
\hline 18 & SUP-REP-70/2017 & & & & \\
\hline 19 & SUP-REP-140/2016 & & & & \\
\hline 20 & SUP-REP-129/2016 & & & & \\
\hline 21 & SUP-REP-122/2016 & & & & \\
\hline 22 & \multirow{3}{*}{$\begin{array}{l}\text { SUP-REP-119/2016 } \\
\text { y acumulado SUP- } \\
\text { REP-120/2016 }\end{array}$} & & & & \\
\hline 23 & & & & & \\
\hline 24 & & & & & \\
\hline
\end{tabular}




\begin{tabular}{|c|c|c|c|c|c|}
\hline \multicolumn{6}{|c|}{ SENTENCIAS EMITIDAS POR SALA } \\
\hline & Sentencias & $\begin{array}{l}\text { Tipo de Violencia } \\
\text { ejercida }\end{array}$ & $\begin{array}{l}\text { ¿Emplea un } \\
\text { enfoque de } \\
\text { perspectiva } \\
\text { de género la } \\
\text { sentencia? }\end{array}$ & $\begin{array}{c}\text { ¿Obstaculiz a } \\
\text { el acceso a la } \\
\text { justicia de la } \\
\text { mujer? }\end{array}$ & $\begin{array}{l}\text { ¿Qué estereotipo } \\
\text { perpetúa la sentencia? }\end{array}$ \\
\hline \multirow{4}{*}{30} & & Violencia & \multirow{4}{*}{ No } & \multirow{4}{*}{ No } & \multirow{4}{*}{$\begin{array}{l}\text { Falta de análisis } \\
\text { probatorio con enfoque } \\
\text { de género: prueba } \\
\text { dinámica }\end{array}$} \\
\hline & & $\begin{array}{l}\text { simbólica a través } \\
\text { del empleo de } \\
\text { lenguaje con }\end{array}$ & & & \\
\hline & SUP-JDC-383/2017 & $\begin{array}{l}\text { estereotipos de } \\
\text { género durante una } \\
\text { campaña electoral } \\
\text { a través de Redes }\end{array}$ & & & \\
\hline & & Sociales & & & \\
\hline \multirow[t]{3}{*}{31} & SUP-JDC-8/2017 & Violencia física & \multirow[t]{3}{*}{ No } & \multirow[t]{3}{*}{ Sí } & \multirow{3}{*}{$\begin{array}{l}\text { Falta de adopción de } \\
\text { medidas cautelares de } \\
\text { proteccióna lavíctima yel } \\
\text { enfoque de perspectiva } \\
\text { de género interseccional, } \\
\text { tratándose del asunto } \\
\text { SUP-JDC-1654/2016 } \\
\text { (Caso Chenalhó, por } \\
\text { tratarse de un asunto } \\
\text { indígena) }\end{array}$} \\
\hline & $\begin{array}{c}\text { SUP-JDC-1773/2016 } \\
\text { y acumulados }\end{array}$ & \multirow{2}{*}{$\begin{array}{l}\text { mediante el } \\
\text { impedimento de } \\
\text { acceso al cargo }\end{array}$} & & & \\
\hline & SUP-JDC-1654/2016 & & & & \\
\hline
\end{tabular}

Análisis propio

${ }^{*} \mathrm{~N} / \mathrm{A}:$ No Aplica

Es decir, de un total de 32 resoluciones que van de 2016 a 2019 (no se encontraron precedentes de 2015 o anteriores) en casi un 82\% está ausente un enfoque de género en torno al análisis del caudal probatorio que obraba en los expedientes, siendo la más frecuente la violencia simbólica por el empleo del lenguaje a través de estereotipos de género durante las campañas electorales (50\%). Sin embargo, tal y como ha sido expresado, la ausencia de un enfoque con perspectiva de género en las resoluciones, demuestra el notorio desconocimiento desde la perspectiva probatoria a favor de la mujer, pues ello hubiese implicado una valoración de los hechos más amplia, en virtud de tratarse el $90 \%$ de la totalidad de asuntos analizados de denuncias, donde debe predominar el principio de interés público, por encima de un interés estricto o particular a diferencia de las demandas de Partidos Políticos por ejemplo.

Por su parte, en el caso de la Sala Regional Especializada del Tribunal Electoral del Poder Judicial de la Federación (TEPJF) la situación es muy similar a la de Sala Superior, adoleciendo claramente de un enfoque de género al momento de evaluar las pruebas de una denuncia dentro de un procedimiento sancionador, tal y como se muestra enseguida. 


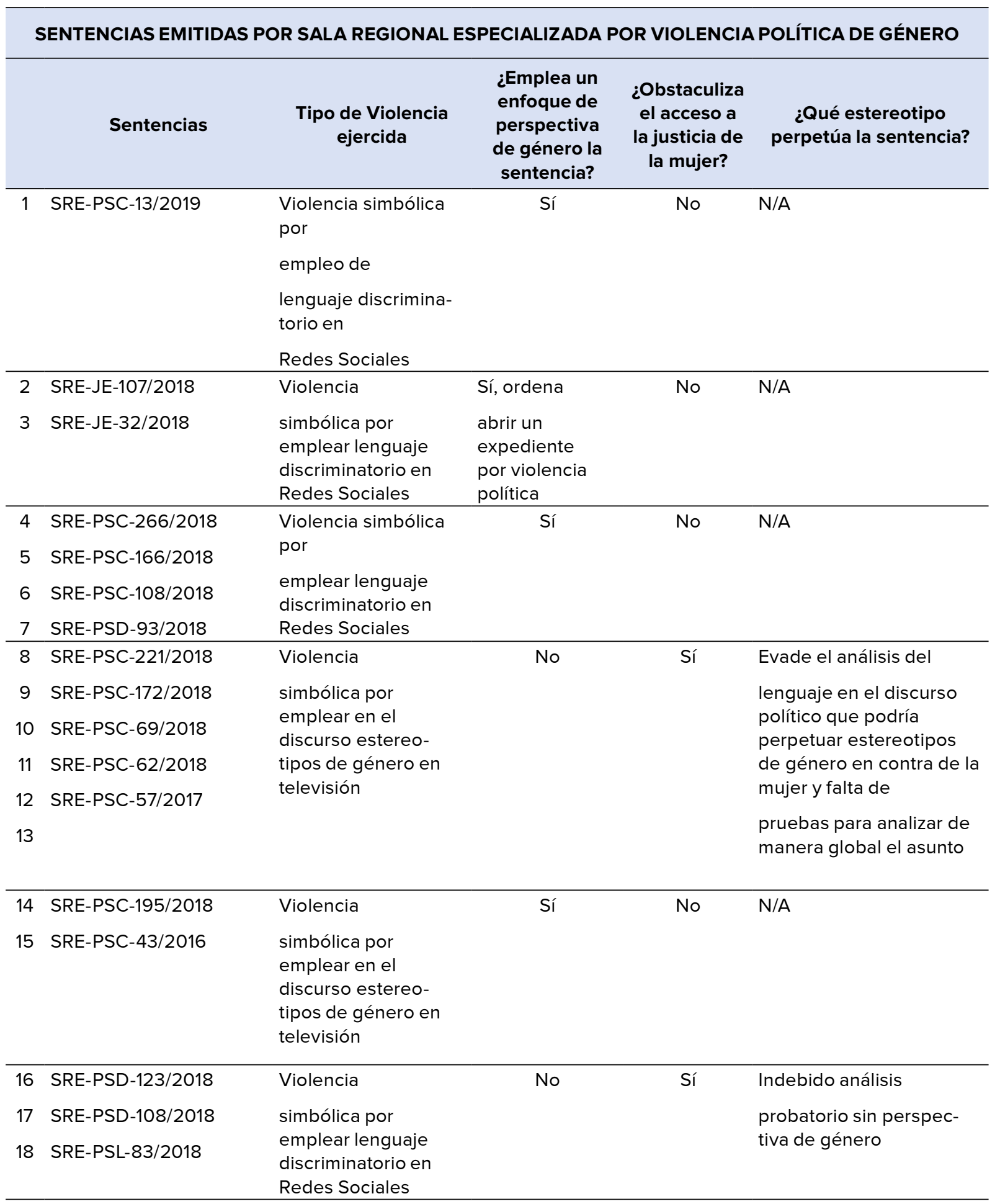

Análisis propio

*N/A: No Aplica 
Una de las diferencias centrales es que en este órgano especializado las denuncias por violencia política de género sucedidas en medios digitales aumenta de manera exponencial en relación con las presentadas en la Sala Superior (55\%). No obstante, tal y como se adelantaba en los resultados anteriores, la Sala Especializada continúa el mismo criterio desgastado de su homóloga, al carecer de una metodología con enfoque de género al momento de valorar todo el caudal probatorio que se le presenta en un caso de violencia política tratándose de medios digitales presentando ante similares hechos criterios divergentes, por no decir contrapuestos uno con otro, sobre todo aquellos que tienen relación con la violencia política de género sucedida en medios tradicionales de difusión como la radio y la televisión.

Las afirmaciones aquí vertidas en torno al deficiente modelo de prueba sin enfoque de género plasmado en las resoluciones aquí criticadas tiene sustento en un sistema de fuente convencional, como la Corte Interamericana de Derechos Humanos, que desde 2006 ha incorporado un estándar de prueba más flexible tratándose de casos donde esté involucrado el tema de violencia de género en contra de la mujer. Concretamente se deben referir diversos asuntos, el primero de ellos es el ocurrido en 2006 (Caso del Penal Miguel Castro vs Perú) donde la Corte Regional desarrolló un estándar probatorio más flexible tratándose de asuntos que guarden relación con la violencia de género, mediante la aplicación de la Convención de Belém do Pará (1994). Uno de los elementos caracterizadores de ese criterio ha sido adoptar que el elemento de género traspasaba la violencia infligida en ellas de manera general, ya que en ese caso concreto, la tortura sufrida por las prisioneras tomó en cuenta la especificidad del género para infligir daño físico y mental, además de atacar la identidad femenina de la mujer.

Igualmente, este Organismo supranacional ha tomado como criterio la ponderación de la evidencia indirecta como las declaraciones de las víctimas así como las pruebas indiciarias (Casos: Rosendo Cantú y otra vs México, 2010; Loayza Tamayo vs Perú, 1997; Chitay Nech y otros vs Guatemala, 2010; Manuel Cepeda Vargas vs Colombia, 2010). Estas pautas hermenéuticas para la valoración de la prueba incluyen además el esclarecimiento judicial oportuno en torno a los actos de violencia sexual además de los perfiles psicológicos y otras pruebas materiales como certificados forenses, entre otros.

\section{Conclusiones}

Tal y como se ha denunciado, se advierte que hasta el día de la presentación de esta propuesta, se carece de una legislación efectiva para atacar de manera frontal la violencia política de género, toda vez que esta infracción no está contemplada en la legislación nacional, siendo únicamente 8 Entidades Federativas las que tienen regulada esta infracción en su legislación, y únicamente 7 Estados tienen el tipo penal de violencia política de género, estando también ausente esta figura jurídica en la Ley General de Delitos Electorales así como recientemente se incorporó a la Ley General de Instituciones y Procedimientos Electorales. Se propone incorporar a los Órganos Electorales de todo el país sobre los criterios y estándares probatorios con los que actualmente se resuelven y castigan las conductas de violencia política de género, será 
crear una propuesta para un mejor diseño legislativo a partir de esta experiencia jurisdiccional de casos judiciales.

Se afirma lo anterior, ya que si bien el Protocolo para Atender la Violencia Política contra las Mujeres es uno de los avances más importantes en los últimos años, es necesario replantear nuevos escenarios a la luz de la violencia suscitada en los últimos años en el país, pero que incluyan sobre todo, asumir nuevos parámetros y estándares probatorios que incluyen pruebas indirectas a fin de generar jurisprudencia género sensitiva (ONU-Órgano Judicial Guatemala, 2015) que deberá incluir además de lo establecido actualmente en el Protocolo para Atender la Violencia Política Contra las Mujeres, incorporen estándares y parámetros de la jurisprudencia de Derecho Internacional de los Derechos Humanos que hagan más dinámica la resolución de casos.

Las formas de discriminación indirecta han mutado y se hacen casi invisibles, máxime que ante el escenario de nuevas tecnologías, se ha transformado de manera vertiginosa la imperiosa necesidad de hacer política. Por consiguiente, es urgente concientizar y brindar las herramientas suficientes que doten tanto a los órganos jurisdiccionales, administrativos y legislativos de las pautas hermenéuticas que sirvan de guía para comprender el fenómeno de la violencia política de género en medios digitales. Por consiguiente, es urgente rediseñar un nuevo modelo para resolver casos de violencia política de género en medios digitales a través de la eliminación de estereotipos empleados comúnmente por el Tribunal Electoral del Poder Judicial de la Federación (TEPJF), Tribunales Electorales locales, Órganos administrativos (Instituto Nacional Electoral -INE y Organismos Públicos Locales Electorales - OPLES) y Fiscalías (Fiscalía Especializada en Delitos Electorales - FEPADE y Fiscalías Especializadas en Delitos Electorales de las Entidades Federativas), dedicados a investigar y sancionar estos hechos.

\section{Referencias bibliográficas}

Bourdieu, P. (2000). La dominación masculina. Barcelona, España: Anagrama

Colección argumentos.

Butler, J. (2007). El género en disputa. El feminismo y la subversión de la identidad. Barcelona: Paidós.

Carreras Presencio, Ana Isabel (2019). Concepto jurídico de violencia de género. Madrid: Dykinson.

Castillejo Mazanares, R. (2020). Política legislativa y violencia de género. Valencia: Tirant lo Blanch.

COIDH (2002) Ficha Técnica Rosendo Cantú y otras Vs. México Recuperado (2020, 27 de enero) https://www.corteidh.or.cr/CF/jurisprudencia2/ficha_tecnica.cfm?nld_Fich=339

Davis, K. (2009) Intersectionality. Intersectionality as buzzword: A sociology of science perspective on what makes a feminist theory successful. Feminist Theory, 2008. SAGE Publications 9(1), pp. 67-85. 
Del Pozo Pérez, Marta (2019). Formación judicial en violencia de género: "análisis crítico". Aranzadi: Pamplona.

DOF CE (2000) Carta de los Derechos Fundamentales de la Unión Europea. Recuperado: (2020, 27 de enero) https://www.europarl.europa.eu/charter/pdf/text_es.pdf

Galtung, J. (1969). Violence, Peace, and Peace Research. Journal of Peace

García del Real, Carlota Bustelo. (1995). "Progresos y obstáculos en la aplicación de la Convención para la eliminación de todas las formas de discriminación contra la mujer" en AA. VV. La protección internacional de los derechos de la mujer tras la Conferencia de Pekín de 1995, (Edición de Fernando M. Mariño Méndez), Instituto de Estudios Internacionales y Europeos <<Francisco de Vitoria>>-Universidad Carlos III de Madrid-Boletín Oficial del Estado, Madrid, 1996, p. 34. Research, 167-191.

Giménez Acosta, Ana (2020). Respuestas del derecho ante la violencia de género desde un enfoque multidisciplinar. Aranzadi: Pamplona.

González Monje, Alicia (2019). La dispensa del deber de declarar en violencia de género. Aranzadi: Pamplona.

INEGI (2019) Encuenta Nacional de Victimización y Percepción sobre Seguridad Pública.

Recuperado INEGI (2020, 27 de enero): https://www.inegi.org.mx/contenidos/programas/ envipe/2019/doc/envipe2019_presentacion_nacional.pdf

INEGI (2016) Encuesta Nacional sobre la Dinámica de las Relaciones en los Hogares (ENDIREH). Recuperado de: (2020, 27 de enero): https://www.inegi.org.mx/programas/endireh/2016/

Lagarde, Marcela (2005) $4^{\mathrm{a}}$ ed. Los cautiverios de las mujeres: madresesposas, monjas, putas, presas y locas. Ciudad de México: UNAM.

Lagarde, Marcela. (1996). Género y feminismo: desarrollo humano y democracia. Siglo Veintiuno Editores. México.

López de Zuribia, S. (2020). Tratamiento de la violencia de género desde la perspectiva criminológica. Madrid: Wolters Kluwer.

OEA (1969) Convención Americana Sobre Derechos Humanos Suscrita en la Conferencia Especializada Inreramicana Sobe Derechos Humanos. Recuperado de: (2020, 27 de enero) https://www.corteidh.or.cr/docs/casos/articulos/seriec_205_esp.pdf

OEA (1988) Protocolo Adicional A La Convencion Americana Sobre Derechos Humanos En Materia De Derechos Economicos, Sociales Y Culturales «Protocolo De San Salvador» Recuperado (2020, 27 de enero) https://eur-lex.europa.eu/legal content/ES/TXT/?uri=L EGISSUM\%3Axy0023\#: : :text=Tratado\%20 constitutivo\%20de\%20la\%20Comunidad\%20 Económica\%20Europea\%20(Tratado\%20CEE).\&text=Estableció\%20la\%20Comunidad\%20 Económica\%20Europea,económico\%20a\%20través\%20del\%20comercio

OEA (1969) Convención Americana Sobre Derechos Humanos Suscrita en la Conferencia Especializada Interamericana sobre Derechos Humanos. Recuperado (2020, 27 de enero) https://www.oas.org/dil/esp/tratados_b32_convencion_americana_sobre_derechos_ humanos.htm 
OEA (1948) Declaración Americana de los Derechos y Deberes del Hombre. Recuperado (2020, 27 de enero) https://www.oas.org/dil/esp/declaración_americana_de_los_derechos_y_ deberes_del_hombre_1948.pdf

ONU Mujeres (2019), Iniciativa Spotlight en el Día Internacional para Eliminar la Violencia contra las mujeres. Recuperado de ONU MUJERES (2020, 27 de enero): https://mexico. unwomen.org/es/noticias-y eventos/articulos/2019/11/spotlighteliminacionviolenciamujeres

Otálora (2017), Participación y Violencia Política Contra Las Mujeres en América Latina: Una Evaluación de Marcos y Prácticas. UNAM: México

Peces Barba Martinez, Gregorio, Curso de Derechos Fundamentales, Universidad Carlos III-B.O.E., Madrid, 1999, p. 283.

Pérez Luo, Antonio Enrique, Dimensiones de la igualdad, Dykinson, Instituto de Derechos Humanos Bartolomé de las Casas-Universidad Carlos III, Madrid, 2005, p. 38.

Sabaté, L. M. (2019). Guía integral para mejor probar la violencia de género. Barcelona: Bosch Editor.

Sánchez Barrios, María (2019). (Des) igualdad y violencia de género. Valencia: Tirant lo Blanch. 